\title{
Analysis of Co, Co2 and No2 AirPollutants in the City of Villavicencio - Colombia
}

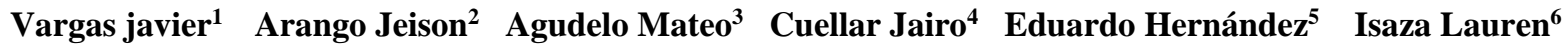 \\ ${ }^{l}$ PhD Educational Sciences, Electronics Engineer. Faculty of Engineering. Cooperative University of Colombia Villavicencio campus. \\ ${ }^{2}$ Magister technologies. Electronic Engineer. Faculty of Engineering. Cooperative University of Colombia Villavicencio campus. \\ ${ }^{3}$ Magister in Environmental Management. Civil engineer. Faculty of Engineering. Cooperative University of Colombia Villavicencio campus. \\ ${ }^{4}$ Magister in Electronic Engineering. Engineering and Basic Sciences Unit, Minute of God University Corporation.- UNIMINUTO \\ ${ }^{5}$ Master in Mechanical Engineering. Engineering and Basic Sciences Unit, Minute of God University Corporation.- UNIMINUTO \\ ${ }^{6}$ Magister Technologies. Electromechanical engineer. Faculty of Mechanical Engineering. University of Santo Tomas Villavicencio \\ ORCIDs: 0000-0001-9726-2661 (Isaza Lauren), 0000-0002-2484-6110(Hernandez ), 0000-0001-6782-1231(Cuellar), \\ 0000-0002-2467-0338 (Agudelo), 0000-0003-2483-5857(Arango), 0000-0001-6208-8659 (Vargas)
}

\begin{abstract}
The article summarizes the results of research, whose purpose was to characterize the behavior of gases $\mathrm{NO} 2, \mathrm{CO}, \mathrm{CO} 2$ present in the city of Villavicencio Meta Colombia. The methodology used was experimental type whose data were processed using descriptive statistical techniques. The results indicated that the gases under study are in the permissible levels by current legal regulations and recommended continued efforts to mitigate the agentsair pollutants in the city.
\end{abstract}

Keywords: Air Quality, CO, CO2, Instrumentation, Descriptive Statistics, Sustainability.

\section{INTRODUCTION}

Colombia ranks second among the 12 different mega nations, with an area of $0.7 \%$ of the surface of the planet, with $10 \%$ of the flora and fauna of the Earth, according to the Research Institute of Biological Resources Alexander von Humboldt likewise alarms are on due to high pollution since it is a problem that is increasing, according to (wHO) Colombia is the second country in Latin America with major environmental problems.

Global warming is a problem that currently increases due to the different sources of contamination, this is produced one of the greatest environmental problems of air pollution, which occurs naturally and / or artificially. Starting from this point, it is important to know in depth each of the variables and factors involved in their development.

The direct consequences that occur in humans due to high levels of air pollution on health are observed. According to official figures, worldwide 3.8 million people die every year from diseases related to pollution of the air, which are pneumonia $(27 \%)$, stroke $(18 \%)$, ischemic heart disease $(27 \%)$, obstructive lung disease occur chronic (20\%) and lung cancer (8\%) (World Health Organization, 2018).

According to the information above, they are notable attempts to lessen the overall impact of air pollution in Colombia. However, these attempts are premature and insufficient, it is necessary to implement better technologies in the major generating sources of pollution such as industry and transport, able to consolidate a culture for the care of the air is another important aspect that can lead to lower economic indices and current health of the country.

Likewise, the purpose of the investigation focused enn determine levels of gaseous pollutants $\mathrm{CO}, \mathrm{NO} 2, \mathrm{CO} 2$, and $\mathrm{O} 3$ present in villavicención, Meta Colombia.

\section{BACKGROUND}

Among the different models to analyze data sets referring to modeling variables contamination of the air for a case study for the city of Medellin (Colombia), where regression models uses of the soil worked in the estimate is Local monthly concentration of pm10, their results were related to indicate the importance of the proper choice of the explanatory variables and access to them for the efficiency of the mathematical model is optimal, likewise, the direct correlation is denoted the closeness between the main roads and traffic density with the concentration of the pollutant PM10 a measurement point [1],statement is consistent with the one in the city of Cali (Colombia) which states that the dynamics of vehicular traffic is primarily responsible for the pollution of air particulate matter PM10, an approach that was developed by using a Spline method modeling the daily behavior of said contaminant [2].

Likewise, in another study conducted in the same city, exactly in the districts 7 and 8 , where he worked with a logistic regression model to assess environmental conditions and pollution under which the risk of presence of contamination Total Suspended Particles (PST) is higher. Worked as variables total suspended particles (TSP) and PM10 particulate material where, from the results of PM10 is possible to obtain a value for PST that can serve as reference for other studies. Moreover, the influence of the climate variable in the presence of pollution that ultimately supported by the model created, you can obtain a measure of the risk of the presence of contamination by PST in the study area is ratified [3]. 
Similarly, the spatial analysis techniques and methods proximity provide a mechanism with which to define the sampling sites studied variables as main roads and secondary, industrial area and green areas; observe the effect of these variables and their possible application to the normative regulation and surveillance systems [4].

Another model used for the development of control systems of quality of the air is the Kriging method, which functions as a guide in the decision to locate a site sampling and analysis costs of implementing the system, given for some regions (developing countries) costs of equipment for sampling are quite high. The method suggests using criteria recommended by the Environmental Protection Agency (EPA) based on the objective of sampling and the characteristics of the sector, such as the population density, the impacts of contaminants known in the art as well as the location of the sources contamination [5].

Another field of study in the development of statistical and scientific models to the problem of air quality should be your early warning. This has been developed several hybrid models from the combination of individual models, such as those discussed above, which are preferred in contributing to the care of the quality of the air and human health, such as neural network model hybrid, optimized algorithm SALP swarm multiobjetivo characterized by having a module data processing, optimization, forecasting and evaluation for better forecasting and warning, which is currently being tested in three cities in China in order to check their efficacy [6]. As well as, methodology neural network multilayer perceptron with which data can be used pollution air (O3, NO NOX, CO, PM10, PM2.5, NO2, bg) and meteorological data (temperature, direction of the wind speed the wind ) to predict with great accuracy the gas contaminant, the above related one of the most disturbing sources of pollution, traffic [7]. Moreover, the implications of traffic flow and weather conditions have been integrated into the simulation model of mesoscopic traffic and simplified estimation models air pollutants can project variables such and, therefrom, predicting and displaying various changes environmental, such as those generated by rising air pollution [8]. Besides the above, in the city of town of Puente Aranda (Bogota, Colombia) has worked in an evolutionary fuzzy model for predicting the level of the quality of the air particulate matter PM10, with a small number of rules, it is possible to obtain satisfactory results predicting this indicator particulate material [9]. Now it is clear that in many of the developing country, methodologies compression and study of the rapidly changing situations have been limited financially, therefore, have developed models combined with which they can develop emissions inventories that to identify the relative contribution of each source of pollution in the region, as in the case of Bogota-Colombia,

After application of study models a procedure is required to assess the appropriateness and objectivity of these being basic components scientific, statistical and operational, ie, the emphasis on accuracy, efficiency and sensitivity of the data ; the predictions of the model compared to the degree of adjustment of the observations to which applicable and finally the operational ease offered by the model evaluated [11]. Such lack of evaluation methods is of vital importance, since for regulators is imperative to know if their investments have paid off, both in cost efficiency, value and justification for public spending, with the aggravating circumstance that every day costs increase with the quality standards of the strictest air [12]. This need has been felt in the UK, because after a successful implementation of local management systems quality of the air to attack sectorally all normative implications that this brings issue with it, it is inherent in the development of methodologies and research to determine the effectiveness of the measures used at different times; actions that result in guides to other local entities in the process, making good policy decisions and the consolidation of an efficient system to simplify query development times in other sectors [13]. In Poland, where there is no clear regulations governing local emissions of individual consumer units,

However, it is to emphasize the advances that have been obtained regarding the evaluation of interventions short and medium term and long term regulations that are implemented over several years. Supported by the results that the current statistical methods, atmospheric modeling and assessing the exposure of humans are obtained, it has been possible to project long term including variables that can occur during the same time period relationships as what is the demographic and economic factors; projections which are still in process and validation replication [12].

Moreover, global human population and urban development are increasing at an unprecedented rate and creating tremendous stress on the quality of air and water at local, regional and global levels. While there is a growing literature linking urbanization and environmental quality, some regions of the world are better represented than others. Moreover, comparison between the rates of population growth and quality of the air and the water suggests that multiple factors affecting the quality of the environment [15].

Because contamination of the air is a problem that primarily affects the large population centers by the development that has generated indisputably unchecked, different countries have entered worry about polluting gases that create the conditions for which are focused on measuring the amount of polluting gases generated so we can implement technologies that promote the reduction of these and thus improving air quality.

Therefore, various studies seeking to identify the biggest polluters of the environment, if the city of Jaipur where the relationship between spatial variables and the concentration of pollutants in the air is examined, finding observed that the concentration of PM10 and SPM has the greatest impact on the environment compared with the air gaseous pollutants (SO2 and NOx) [16]. With the same purpose in the region of Malaysia sought to determine and assess levels of BTEX in the air over selected areas. Determining that the vehicle emissions are the main source of generation of this contaminant and the risk of cancer is based on benzene concentrations in urban and suburban areas [17]. These examples show that large population areas developments are the main sources of atmospheric pollutants. Caused by the 
implementation of large industries and the effect of mainly mobilization.

To meet the challenges associated with such rapid urbanization, it has become necessary to implement smart strategies for environmental management and planning, addressing the unique demands of urban areas to maintain environmental sustainability and work with minimal interruption. Fernando proposes to "start a new focus area, urban fluid mechanics (UFM, for its acronym in English), designed to investigate these issues. To achieve optimal social impact, the UFM must deepen flow problems fundamental and applied fluid immediately useful for the development of urban public policies and environmental regulations. " [18].

A the same time must be integrated information systems that promote interaction of spatial and environmental variables for characterizing the quality of the air inside an urban area. Through a combination of expert systems and tools to support decision making, possessing the ability to receive information from in situ measurements such as environmental telematics posed within a framework for the development of management systems quality of urban air present a comprehensive approach to the implementation and evaluation of relevant scenarios "[19].

As it stated the rapid increase in urbanization is one of the main factors contributing to deterioration of the quality of the air, however, other aspects that are interrelated and promote greater effects of air pollution, such as infrastructure and transport.

Humans spend a considerable amount of time breathing air in closed spaces where, due to various sources, there may be contaminants that deteriorate the quality of the air. This is a major risk factor for the health of the general population. [twenty].

Microorganisms such as fungi, bacteria and biological particles are involved in generating pollution inside buildings, causing deterioration of infrastructure and in some cases, health problems. This paper introduces the general aspects of microbial contamination inside buildings and seeks to provide a perspective on the potential influence of microorganisms as etiologic agents of respiratory diseases and allergies type [21].

In [22] presents the study of concentrations of fine particles (PM10)), culturable bacteria in the air (CAB), Total volatile organic compounds (TVOC), formaldehyde (HCHO), $\mathrm{CO} 2$, $\mathrm{NO} 2$ and $\mathrm{O} 3$ in 59 station facilities Metro and public parking at a national level in Korea of the South, where possible relationships of pollutants were analyzed indoors with underground environmental factors and characteristics of facilities that evidence lower concentrations to the outdoors in all facilities.

To illustrate another situation we have the case of Portugal, where the influence was assessed a package of resilience solutions based on nature, wind flow and dispersion of air pollutants. Given two pollutants (NOx and PM10) and four scenarios: i) a stage basis, ii) an urban green stage, iii) a stage of green roof, and iv) a "gray" stage (without trees). Overall, the results showed that strategic location of vegetation in cities has the potential to make an important contribution to improving air quality and sustainability of urban environments [23].

\section{METHOD}

The study design was based on quantitative research of experimental type, delimited by three phases. Phase 1 , Identifying the main sources that contribute to air pollution in the area under study georeferencing. Stage 2, measurement of the gaseous pollutants $\mathrm{CO}, \mathrm{CO} 2$ and $\mathrm{NO} 2$. Phase 3, descriptive statistical analysis to determine the behavior of gases under study in the georeferenced area. Phase 4 presents an analysis of the results against national and international legislation.

For the execution of these phases electronic instrumentation system was used with graphical user interface. The analysis focused on $\mathrm{CO}, \mathrm{CO} 2$ and $\mathrm{NO} 2$ gases. In Figure 1, the graphical user interface used is presented.

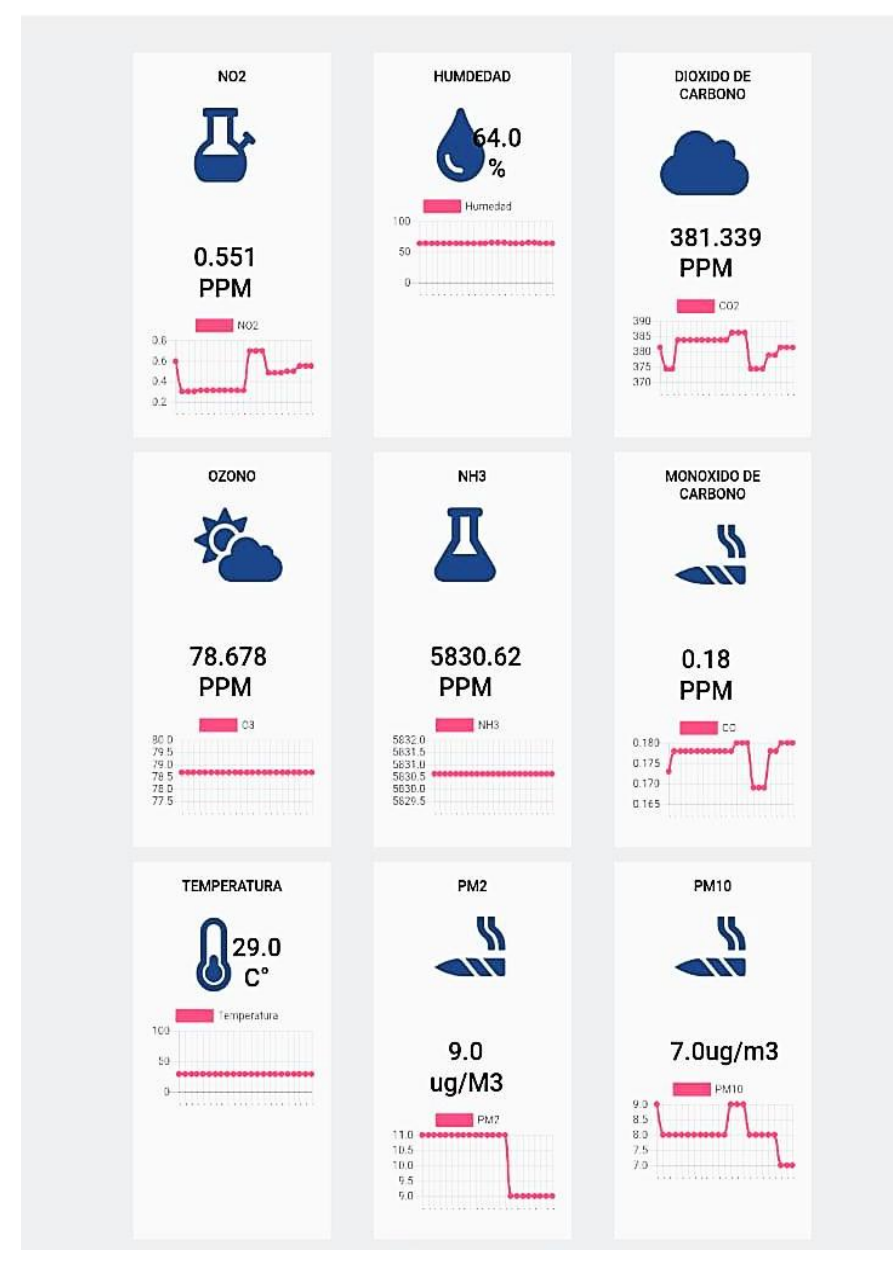

Figure 1. Graphical User Interface instrument measurement of $\mathrm{CO}$ and $\mathrm{CO} 2$ 
Regarding the current legal regulations it is presented in chronological order resolutions and documentation relevant to the issue of air quality.

Table 1. legal regulations in force

\begin{tabular}{|c|c|c|}
\hline regulatory & Year & Observation \\
\hline resolution 391 & 2001 & $\begin{array}{l}\text { stricter standards were established and included pollutants that had not been covered by the } \\
\text { national regulation in the capital city - Bogotá }\end{array}$ \\
\hline law 631 & 2001 & production, marketing and consumption of ethanol and biodiesel as fuel is driven \\
\hline resolution 1208 & 2003 & 391 resolution repealing and objectives established environmental quality \\
\hline law 939 & 2004 & $\begin{array}{l}\text { production and marketing of biofuels of vegetable or animal origin for use in diesel fuel is } \\
\text { promoted. }\end{array}$ \\
\hline CONPES 3344 & 2005 & $\begin{array}{l}\text { With which it is oriented on the development of intersectoral policies and strategies } \\
\text { focused on prevention and control of air pollution in cities and industrial areas of } \\
\text { Colombia. }\end{array}$ \\
\hline decree 979 & 2006 & Whereby items 7,10, 93, 94 and 108 of Decree 9481995 modified. \\
\hline resolution 601 & 2006 & a method of regulating greater detail ranking source of contamination areas- \\
\hline law 1083 & 2006 & $\begin{array}{l}\text { Through which some rules are established on sustainable urban planning and other } \\
\text { provisions }\end{array}$ \\
\hline resolution 909 & 2008 & $\begin{array}{l}\text { With which which they set standards and emission standards for industry, as well as } \\
\text { emission measurement procedures and development agreements conversion to cleaner } \\
\text { technologies }\end{array}$ \\
\hline resolution 910 & 2008 & $\begin{array}{l}\text { pollutant emission levels are established by the air vehicles and motorcycles and their } \\
\text { regulatory requirements and certification }\end{array}$ \\
\hline law 1205 & 2008 & In which the regulation is issued seeking to improve the quality of diesel fuel. \\
\hline CONPES 3550 & 2008 & $\begin{array}{l}\text { With which sought to strengthen the comprehensive management of environmental health- } \\
\text { oriented prevention, management and control of adverse health effects resulting from } \\
\text { environmental factors }\end{array}$ \\
\hline resolution 2604 & 2009 & $\begin{array}{l}\text { With which limpios } 46 \text { fuels are determined and regulated the maximum allowable } \\
\text { emission test dinámica } 47 \text { for vehicles associated with the provision of public service inland } \\
\text { transport of passengers and motocarros } 48 \text { linked to the provision of public ground } \\
\text { transportation service with mixed automotive. }\end{array}$ \\
\hline resolution 941 & 2009 & $\begin{array}{l}\text { the National Register Environmental (RUA) is adopted with which information on the use } \\
\text { and exploitation of natural resources is captured by the productive sectors }\end{array}$ \\
\hline resolution 6982 & 2011 & $\begin{array}{l}\text { With which the resolution } 391 \text { and repealing regulations are updated to new demands } \\
\text { atmospheric conditions Bogota }\end{array}$ \\
\hline resolution 760 & 2010 & A protocol is adopted for the control and monitoring pollution generated by fixed sources \\
\hline resolution 650 & 2010 & $\begin{array}{l}\text { With which the protocol is adopted for monitoring and tracking the quality of the air, } \\
\text { which contains an overview of the Surveillance Systems Air Quality (ACLS) }\end{array}$ \\
\hline resolution 651 & 2010 & $\begin{array}{l}\text { With which the Information Subsystem Air Quality (Sisaire) is created as a primary source } \\
\text { of information for the design, evaluation and adjustment of national and regional policies } \\
\text { and strategies for prevention and control of pollution of the air }\end{array}$ \\
\hline
\end{tabular}




\begin{tabular}{|c|c|c|}
\hline regulatory & Year & Observation \\
\hline $\mathbf{N} / \mathbf{A}$ & 2010 & $\begin{array}{l}\text { The Council National Environment adopted the Policy on Prevention and Control of } \\
\text { Pollution of the air, in order to encourage management to achieve adequate to protect } \\
\text { human health and welfare standards of quality of the air, in the context of sustainable } \\
\text { development }\end{array}$ \\
\hline decree 98 & 2011 & $\begin{array}{l}\text { Decennial Plan Decontamination is adopted in the air of Bogota, as the first plan for } \\
\text { prevention, reduction and control of air pollution in the country }\end{array}$ \\
\hline decree 1076 & 2015 & $\begin{array}{l}\text { Through which the Single Regulatory Decree is issued by the Environment and Sustainable } \\
\text { Development Sector and a compilation of all existing regulations is made regarding } \\
\text { sustainable environment and development sectors }\end{array}$ \\
\hline decree 1077 & 2015 & $\begin{array}{l}\text { Through which the Single Regulatory Decree is issued in the housing sector, city and } \\
\text { territory, which states that the municipalities and districts must develop mobility plans } \\
\text { where prevail mobilization in alternative modes of transport and the use of clean fuels in } \\
\text { public transport systems. }\end{array}$ \\
\hline decree 1625 & 2016 & $\begin{array}{l}\text { In which the decrees } 2532200131722003 \text { are compiled, with which the only Decree on } \\
\text { tax matters with which benefits are granted tax (VAT and income) is defined projects, } \\
\text { programs or activities reduced consumption energy or energy efficiency to go towards } \\
\text { achieving environmental goals }\end{array}$ \\
\hline resolution 1988 & 2017 & $\begin{array}{l}\text { In which how the environmental goals of energy efficiency with the introduction of electric } \\
\text { vehicles, dedicated to natural gas and hybrid } 41286 \text { according to resolution } 2016 \text { of the } \\
\text { Ministry of Mines and Energy }\end{array}$ \\
\hline decree 1116 & 2017 & $\begin{array}{l}\text { Whereby reduced tariff for electric and hybrid vehicles approved with } 0 \% \text { and } 5 \% \\
\text { respectively }\end{array}$ \\
\hline resolution 2254 & 2017 & $\begin{array}{l}\text { By which standards air quality and measures for preventing care episodes, emergency alert } \\
\text { and that previous rules were established more restrictive levels. This, in response to the } \\
\text { proposed guideline values for air quality by WHO }\end{array}$ \\
\hline CONPES 3918 & 2018 & $\begin{array}{l}\text { With which they pose strategies for the implementation of Sustainable Development Goals } \\
\text { (SDGs) in Colombia }\end{array}$ \\
\hline CONPES 3934 & 2018 & $\begin{array}{l}\text { It describes a roadmap is established to guide the country to a transition towards a more } \\
\text { sustainable economic model, strategies aimed at the efficient and productive use of natural } \\
\text { resources and reducing the environmental and social impact from productive activities } \\
\text { (National Council Social and Economic Policy, 2018) }\end{array}$ \\
\hline
\end{tabular}

\section{RESULTS}

The results, presented measurements and statistical analysis which describes the behavior of the data for each of the gases, $\mathrm{NO} 2, \mathrm{CO}$ and $\mathrm{CO} 2$. Table 2 shows the statistical data to dioxide Table 3 presents statistical data for carbon monoxide (CO) evaluated in a period of five weeks. Likewise, Figure 3 shows the histogram and the normal distribution curve of the data obtained from the $\mathrm{CO}$ during the 5 weeks of monitoring. Nitrogen over a period of five weeks. Also, Figure 2 shows the histogram and the normal distribution curve of the data of NO2 during 5 weeks of monitoring.

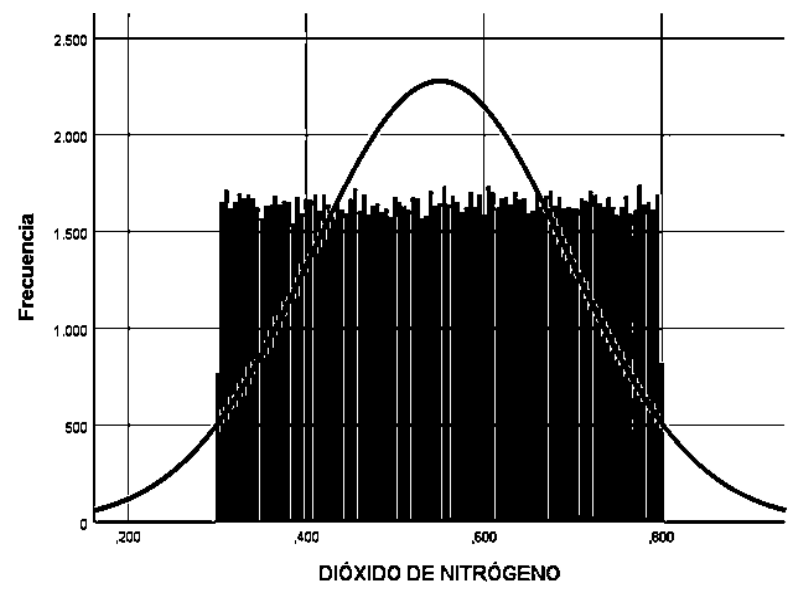

Figure 2. Histogram distribution curve and standard NH2 
International Journal of Engineering Research and Technology. ISSN 0974-3154 Vol.13, No.3 (2020), pp. 490-499

(C) International Research Publication House. https://dx.doi.org/10.37624/IJERT/13.3.2020.490-499

Table 2. Statistical data Nitrogen Dioxide NO2

\begin{tabular}{|c|c|c|c|c|c|c|c|}
\hline \multicolumn{2}{|c|}{$\mathrm{NO2}$} & \multirow{2}{*}{$\begin{array}{c}\text { WEEK } 1 \\
21805\end{array}$} & \multirow{2}{*}{$\begin{array}{c}\text { WEEK } 2 \\
30982\end{array}$} & \multirow{2}{*}{$\begin{array}{c}\text { Week } 3 \\
40491\end{array}$} & \multirow{2}{*}{$\begin{array}{c}\text { WEEK } 4 \\
34265\end{array}$} & \multirow{2}{*}{$\begin{array}{c}\text { Week } 5 \\
37299\end{array}$} & \multirow{2}{*}{$\begin{array}{c}\text { TOTAL } \\
164843\end{array}$} \\
\hline $\mathbf{N}$ & Valid & & & & & & \\
\hline & lost & two & 0 & one & two & two & one \\
\hline \multicolumn{2}{|l|}{ Half } & 0.54988 & 0.55 & 0.55093 & .5497 & 0.55052 & 0.55027 \\
\hline \multicolumn{2}{|l|}{ Median } & 0.551 & 0.551 & 0.552 & 0.549 & 0.552 & 0.55100 \\
\hline \multicolumn{2}{|l|}{ fashion } & 0,66 & 0,327 & 0.633 & 0.463 & 0.506 & 0,660 \\
\hline \multicolumn{2}{|c|}{ Desv. Deviation } & 0.144411 & 0.144249 & 0.143878 & 0.144654 & 0.144603 & 0.144363 \\
\hline \multicolumn{2}{|l|}{ variance } & 0,021 & 0,021 & 0,021 & 0,021 & 0,021 & 0,021 \\
\hline \multicolumn{2}{|l|}{ Asymmetry } & -0.005 & -0.01 & -0.01 & 0,007 & -0.007 & -0.005 \\
\hline \multicolumn{2}{|c|}{$\begin{array}{l}\text { standard error of } \\
\text { skewness }\end{array}$} & 0,017 & 0,014 & 0,012 & 0,013 & 0,013 & 0,006 \\
\hline \multicolumn{2}{|l|}{ kurtosis } & -1.203 & -1.208 & -1.191 & -1.2 & -1.199 & -1.199 \\
\hline \multicolumn{2}{|c|}{$\begin{array}{l}\text { standard error of } \\
\text { kurtosis }\end{array}$} & 0,033 & 0,028 & 0,024 & 0,026 & 0,025 & 0,012 \\
\hline \multicolumn{2}{|l|}{ Rank } & 0.5 & 0.5 & 0.5 & 0.5 & 0.5 & 0,500 \\
\hline \multicolumn{2}{|l|}{ Minimum } & 0.3 & 0.3 & 0.3 & 0.3 & 0.3 & 0,300 \\
\hline \multirow{4}{*}{$\begin{array}{l}\text { Maximum } \\
\text { percentiles }\end{array}$} & & 0.8 & 0.8 & 0.8 & 0.8 & 0.8 & 0,800 \\
\hline & 25 & 0.424 & 0.424 & 0.427 & 0.424 & 0,425 & 0.42500 \\
\hline & 50 & 0.551 & 0.551 & 0.552 & 0.549 & 0.552 & 0.55100 \\
\hline & 75 & 0.675 & 0.676 & 0.674 & 0.674 & 0.676 & 0.67500 \\
\hline
\end{tabular}

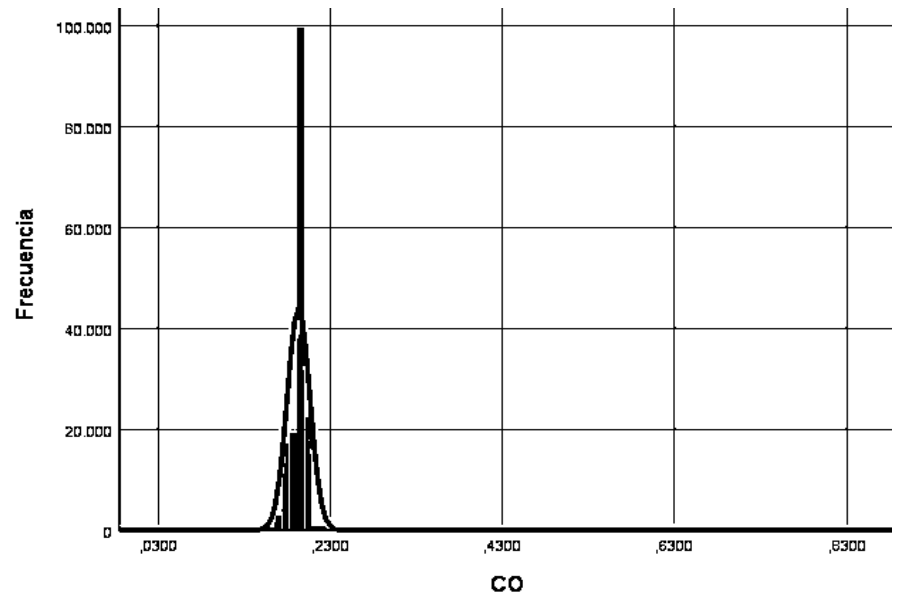

Figure 3. Histogram and standard distribution curve $\mathrm{CO}$

Within the study period shows that the variation does not exceed $0.005 \mathrm{ppm}$ compared to the total global figure of 0.193234 PPM. A the same time data of the standard error of the mean reflect a high degree of accuracy of the determined average as the values are close to zero and the global data which is 0.0000320 .

Furthermore, a ratio of median values with the average, especially in the total value of the data is reflected as in both cases corresponds to 0193 PPM. In the case of global fashion can be considered multimodal, because in week 2, 3,4 and 5 the same value 0193 is present and only consider week one as modal, ie the tendency of variation of the $\mathrm{CO}$ in the study period it is the same.

Also, the asymmetry value calculated that is above 0 , this value is 9.527 to its reflects time data presented for $\mathrm{CO}$ in general are not symmetrical. Similarly it is considered that the precision of the coefficient of asymmetry is quite high since the error of asymmetry (0.006) is close to 0 . Moreover, kurtosis 266.443 global data is considered so leptokurtic and indicates that the distribution has heavier tails than the normal distribution, because the value found is significantly above 0 ; in turn it is considered fairly accurate information because the error kurtosis is 0.012 . 
International Journal of Engineering Research and Technology. ISSN 0974-3154 Vol.13, No.3 (2020), pp. 490-499

(C) International Research Publication House. https://dx.doi.org/10.37624/IJERT/13.3.2020.490-499

Table 3. Statistical data Nitrogen Dioxide CO

\begin{tabular}{|c|c|c|c|c|c|c|c|}
\hline \multicolumn{2}{|c|}{ Statistical data } & \multirow{2}{*}{$\begin{array}{r}\text { Week 1 } \\
23506\end{array}$} & \multirow{2}{*}{$\begin{array}{r}\text { week } 2 \\
30982\end{array}$} & \multirow{2}{*}{$\begin{array}{r}\text { week } 3 \\
40491\end{array}$} & \multirow{2}{*}{$\begin{array}{r}\text { week } 4 \\
34266\end{array}$} & \multirow{2}{*}{$\begin{array}{r}\text { week } 5 \\
37301\end{array}$} & \multirow{2}{*}{$\begin{array}{l}\text { Total } \\
164842\end{array}$} \\
\hline $\mathbf{N}$ & valid & & & & & & \\
\hline & lost & one & 0 & one & one & 0 & two \\
\hline \multicolumn{2}{|l|}{ Half } & , 199049 &, 191334 &, 191860 &, 191131 &, 194459 &, 193234 \\
\hline \multicolumn{2}{|c|}{ Error typ. the average } &, 000142 &, 000033 &, 000077 &, 000043 &, 000064 &, 000032 \\
\hline \multicolumn{2}{|l|}{ Median } & , 203000 &, 193000 &, 193000 &, 193000 &, 193000 &, 193000 \\
\hline \multicolumn{2}{|l|}{ fashion } &, 206000 &, 193000 &, 193000 &, 193000 &, 193000 &, 193000 \\
\hline \multicolumn{2}{|l|}{ Desv. typ. } &, 021796 &, 005833 &, 015527 &, 007874 &, 012326 &, 013010 \\
\hline \multicolumn{2}{|l|}{ variance } &, 000475 &, 000034 &, 000241 &, 000062 &, 000152 &, 000169 \\
\hline \multicolumn{2}{|l|}{ Asymmetry } & 1.67016 & -1.27317 & 12.15105 & -17979 & 9.64191 & 9.52652 \\
\hline \multicolumn{2}{|c|}{ Error typ. asymmetry } &, 015976 &, 013916 &, 012173 &, 013232 &, 012682 &, 006033 \\
\hline \multicolumn{2}{|l|}{ kurtosis } & 97.0987 & 4.6005 & 252.9021 & 1.4722 & 215.3625 & 266.4432 \\
\hline \multicolumn{2}{|c|}{ Error typ. kurtosis } &, 031950 &, 027830 &, 024344 &, 026463 &, 025364 &, 012066 \\
\hline \multicolumn{2}{|l|}{ Rank } &, 808000 &, 077000 &, 570000 &, 117000 & , 458000 & , 808000 \\
\hline \multicolumn{2}{|l|}{ Minimum } & , 030000 &, 155000 &, 146000 &, 146000 &, 145000 &, 030000 \\
\hline \multicolumn{2}{|l|}{ Maximum } &, 838000 &, 232000 &, 716000 &, 263000 &, 603000 &, 838000 \\
\hline \multirow[t]{3}{*}{ percentiles } & 25 &, 193000 &, 193000 &, 190000 &, 185000 &, 193000 &, 193000 \\
\hline & 50 & , 203000 & , 193000 & , 193000 & , 193000 &, 193000 &, 193000 \\
\hline & 75 &, 206000 &, 193000 &, 193000 &, 193000 &, 195000 &, 195000 \\
\hline
\end{tabular}

Table 4 shows the statistical data corresponding to the carbon dioxide (CO2) evaluated in a period of five weeks. Likewise, Figure 4 shows the histogram and the normal distribution curve of the data of the $\mathrm{CO} 2$ during 5 weeks of monitoring.

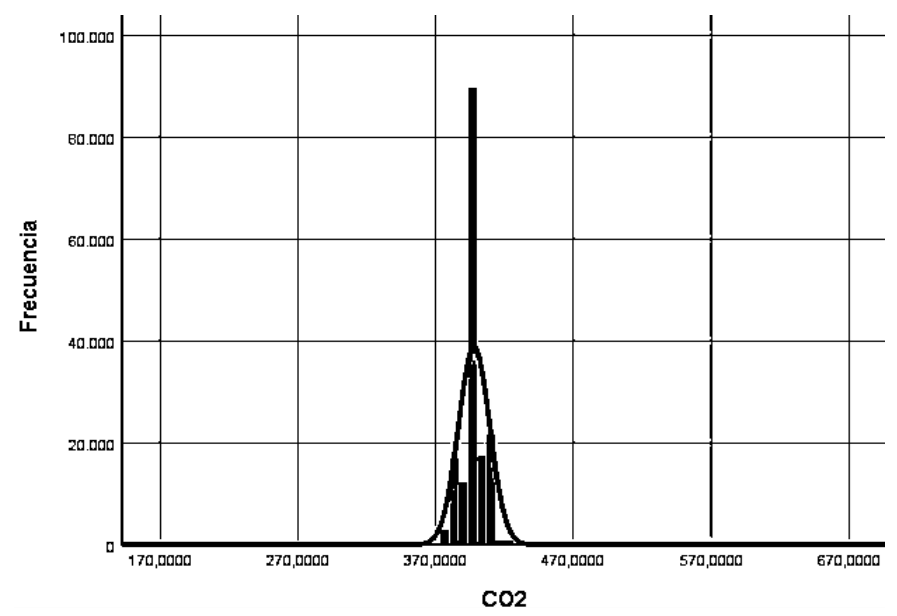

Figure 4. Histogram and standard distribution curve $\mathrm{CO}$

For the analysis period is 397.946 PPM as an average of the total of the data for variable $\mathrm{CO} 2$, and comparing this value with the average score for each week found that the mean difference for each week compared to the ranges overall between 1.1 and 1.8 PPM except week 1 having a greater difference with 4.76 PPM of the global average. Similarly, to the error analysis of the average we found a high degree of accuracy of the calculated means, being the highest error 0.146 in week 1, reflecting data inconsistencies by which it is separated from the overall average.

A median analyzing the data obtained can be seen a relation of symmetry between them, especially in the values as the mean and median values have 397.913397 .946 and respectively. On the other hand, global fashion can be considered multimodal, because in week 2, 3, 4 and 5 the same value 397.913 present and would only be considered the week 1 as modal, ie the trend of variation of $\mathrm{CO} 2$ in the study period it is the same.\}

In this statistical analysis we consider the skewness and kurtosis. For total global data graph No. 55, wherein a right skewed distribution, which can be checked with the asymmetry value calculated that is above 0 , is evidenced presents this value of 3051 in turn shows that the data presented for $\mathrm{CO} 2$ in general are not symmetrical. Similarly, it is considered that the precision of the asymmetry coefficient is quite high because the asymmetry error $(0.006)$ is very close to 0 . 
Moreover, kurtosis 143,291 global data is considered so leptokurtic and indicates that the distribution has heavier tails than the normal distribution, because the value found is significantly above 0 ; in turn it is considered fairly accurate information because the error kurtosis is 0.012 .

Table 4. Statistical data Nitrogen Dioxide $\mathrm{CO} 2$

\begin{tabular}{|c|c|c|c|c|c|c|c|}
\hline \multicolumn{2}{|c|}{ Statistical data } & Week 1 & week 2 & week 3 & week 4 & week 5 & Total \\
\hline \multirow[t]{2}{*}{$\mathbf{N}$} & lid & 23507 & 30982 & 40492 & 34267 & 37300 & 164844 \\
\hline & & 0 & 0 & 0 & 0 & one & 0 \\
\hline \multicolumn{2}{|l|}{ Half } & 402.70252 & 396.37837 & 396.66348 & 396.06814 & 399.08722 & 397.946323 \\
\hline \multicolumn{2}{|c|}{ Error typ. the average } &, 146134 &, 031033 &, 061653 &, 039379 &, 053645 &, 0277846 \\
\hline \multicolumn{2}{|l|}{ Median } & 407.20100 & 397.9130 & 397.9130 & 397.9130 & 397.9130 & 397.9130 \\
\hline \multicolumn{2}{|l|}{ fashion } & 409.600 & 397.913 & 397.913 & 397.913 & 397.913 & 397.9130 \\
\hline \multicolumn{2}{|l|}{ Desv. typ. } & 22.405321 & 5.462283 & 12.40623 & 7.289594 & 10.36047 & 11.28083 \\
\hline \multicolumn{2}{|l|}{ variance } & 501.998 & 29.837 & 153.915 & 53.138 & 107.339 & 127.257 \\
\hline \multicolumn{2}{|l|}{ Asymmetry } & -4.145 & -1.410 & 8,411 &,- 292 & 6,161 & 3,051 \\
\hline \multicolumn{2}{|c|}{ Error typ. asymmetry } & 016 & 014 & 012 & 013 & 013 & 006 \\
\hline \multicolumn{2}{|l|}{ kurtosis } & 58.886 & 5,189 & 138.543 & 1,573 & 107.449 & 143.291 \\
\hline \multicolumn{2}{|c|}{ Error typ. kurtosis } &, 032 &, 028 & 024 &, 026 &, 025 & 012 \\
\hline \multicolumn{2}{|l|}{ Rank } & 612.927 & 75.228 & 419.179 & 105.284 & 320.756 & 612.9270 \\
\hline \multicolumn{2}{|l|}{ Minimum } & 171.763 & 357.575 & 303.499 & 350.510 & 348.027 & 171.7630 \\
\hline \multicolumn{2}{|l|}{ Maximum } & 784.690 & 432.803 & 722.678 & 455.794 & 668.783 & 784.6900 \\
\hline \multirow[t]{3}{*}{ percentiles } & 25 & 397.91300 & 397.9130 & 395.4990 & 390.7690 & 397.9130 & 397.7450 \\
\hline & 50 & 407.20100 & 397.9130 & 397.9130 & 397.9130 & 397.9130 & 397.9130 \\
\hline & 75 & 409.60000 & 397.9130 & 397.9130 & 397.9130 & 400.1900 & 400.1900 \\
\hline
\end{tabular}

\section{DISCUSSION AND CONCLUSIONS}

According to the calculated values and presented in Table 5, it is stated that none of the gases exceeds permissible limits.

Table 4. Statistical data Nitrogen Dioxide CO2

\begin{tabular}{|c|c|c|c|c|}
\hline \multirow[t]{2}{*}{ polluting gas } & \multirow[t]{2}{*}{ permissible level } & \multicolumn{2}{|c|}{ current level } & \multirow[t]{2}{*}{ Parameter Verification } \\
\hline & & ug / m3 * hour & PPM & \\
\hline Nitrogen dioxide & 200 (1 hour) (g / m3) & 69.029 & & meets \\
\hline Ozone & 100 (8 hours) $(\mathrm{g} / \mathrm{m} 3)$ & 71.848 & & meets \\
\hline Carbon monoxide & 5000 ( 1 hour) or 35000 ( 8 hours $)(\mathrm{g} / \mathrm{m} 3)$ & 14.758 & & meets \\
\hline Ammonia & 100 (ppm) & & 0.846 & meets \\
\hline Carbon dioxide & 5000 (ppm) & & 397.946 & meets \\
\hline
\end{tabular}

Regarding Nitrogen Dioxide (NO2) has been shown that for short exposure times may capacity bronchial responsiveness in asthmatics is directly affected when the levels are equal or greater than $200 \mathrm{~g} / \mathrm{m} 3$. lung function also, when these levels reach concentrations exceeding $500 \mathrm{mg} / \mathrm{m} 3$ directly affected causing a reaction even more critical health over a period of one hour. On the other hand, it has also been proven that exposure to NO2 in periods of annual time increase symptoms of bronchitis in asthmatic children and lung function in relation to high concentrations of the gas in a span of one year (WHO, 2005)

Similarly, carbon monoxide (CO) reacts to the inhaled reducing oxygen transport in the blood, depending on the concentration and duration of exposure, by a mild poisoning some effects are weakness, fatigue, tendency to sleep, headache, nausea, vomiting, chest pain and rapid pulse. In 
cases of increased exposure can manifest seizures, slow heartbeat, respiratory arrest and low blood pressure. Also, as for chronic effects, prolonged exposure increases the risk in heart problems and gradually increasing damage to the nervous system in extreme cases can occur cancer (The LINDE Group, 2012)

Finally, to carbon dioxide $(\mathrm{CO} 2)$ is the most powerful cerebral vasodilator known. Inhaling large concentrations causes rapid circulatory insufficiency leading to coma and death. Low concentrations of carbon dioxide cause increased respiration and headache. The effects can include: rapid breathing, diminished mental alertness, impaired muscular coordination, faulty judgment, depression of all sensations, emotional instability and fatigue. A progressing choking nausea, vomiting, prostration and unconsciousness, eventually leading to convulsions, coma and death can occur.

\section{ACKNOWLEDGEMENTS}

The authors wish to thank the Minuto de Dios Corporation and the Universidad Cooperativa de Colombia for their contribution to the funding of the project under study. Also to the Research Assistants Iván Andrés Acosta Cárdenas, Karen Dayana Diaz Pastrana, Natalia Del Pilar Huiza Fandiño, for their collaboration during the research process.

\section{REFERENCES}

[1] Antonio, L., Ciro, L., Eduardo, J., \& Barriga, C. (2015). Methodology for applying regression models Uses Of Soil In estimating Local Monthly concentration of PM10 in Medellin - Colombia, 11 (21), 29-40.

[2] Jhovana, R., \& Javier, O. (2012). By curve fitting nonparametric methods to study the behavior of contamination of airborne PM10 Particulate Material.

[3] Susan L., BO, Alejandra, T., \& Javier, OO (2004). Total Suspended Particulate contamination in co munas 6 and 7 of Cali, Colombia A statistical model for evaluating the quality of the air. Engineering Natural Resources and Environment,

[4] Libardo, A., July, E., Julian D., \& Giraldo-Ocampo, JD (2017). Model spatial proximity to define sampling sites in urban networks define air quality sampling sites in urban air quality networks, 35. https://doi.org/10.17533/udea.rfnsp.v35n1a12

[5] Bayraktar, H. (2005). A Kriging-based approach for locating a sampling site - in the assessment of air quality, 301-305. https://doi.org/10.1007/s00477-0050234-8

[6] Hao, Y., \& Tian, C. (2019). The study and application of a novel hybrid system for air quality early-warning. Applied Soft Computing Journal, 74, 729746.https://doi.org/10.1016/j.asoc.2018.09.005
[7] Richard, B., Sheen Mclean, SC, \& John Kaiser, SC (2017). Hybrid Artificial Neural Network Models for Effective Prediction and Mitigation of Urban Pollution Roadside NO 2. Energy came, 142, 3524-3530. https://doi.org/10.1016/j.egypro.2017.12.240

[8] Simona, A., Ortiz, MB, Camargo, M., \& Cai, C. (2018). Predicting Air Quality by Integrating a Mesoscopic Traffic Simulation Model and Simplified Air Pollutant Estimation Models.

[9] Varela, R., Albert, C., Rey, M., Albert, M., Varela, A., Nieto, A., \& Deicy, L. (2012). Evolutionary Fuzzy System for Predicting the level of contamination of the air for Particulate Matter: Case Puente Aranda (Bogotá) Genetic Fuzzy System for the prediction of air pollution level by Particulate Matter - Case study: Summary Bogotá. Engineering, 17, 55-62.

[10] Belalca, LC, Clappier, A., Manzi, V., \& Za, E. (2007). Air quality modeling over Bogota, Colombia: Combined techniques to estimate emission inventories and evaluate-, 41, 6302-6318.

[11] Chang, JC, \& Hanna, SR (2004). Air quality performance evaluation model, 196, 167-168. https://doi.org/10.1007/s00703-003-0070-7

[12] Erp, AM Van, Kelly, FJ, \& Cohen, AJ (2012). Progress in research to ASSESS the effectiveness of air quality Improving public health interventions towards, 217230.

[13] Beattie, CI, Longhurst, JWS, \& Woodfield, NK (2000). Air Quality Management: Challenges And Solutions In Action Delivering Air Quality Plans, 729-747.

[14] Adamczyk, J. (2017). Air Protection Programs in Poland in the context of the low emission, 1631616327.https://doi.org/10.1007/s11356-017-9233-9

[15] Duh, J. Der, Shandas, V., Chang, H., \& George, LA (2008). Rates of urbanization and the resiliency of air and water quality. Science of the Total Environment, 400 (1-3), 238-256.

[16] Assessment, AN, Urban, OF, Expansion, S., On, I., Quality, AIR, \& Geospatial, U. (2017). Ee an Assessment of Urban Space and Its Expansion, 79-87.

[17] Hamid, HHA, Latif, MT, Nadzir, MSM, uning, R. Khan, MF, \& Kannan, N. (2019). Ambient BTEX levels over urban, suburban and rural areas in Malaysia. Air Quality, Atmosphere and Health, 3.https://doi.org/10.1007/s11869-019-00664-1.

[18] Fernando, HJS, Lee SM, Anderson, J., Princevac, M., Pardyjak, E., \& Grossman-Clarke, S. (2001). Urban Fluid Mechanics: Air Circulation and Contaminant Dispersion in Cities. Environmental Fluid Mechanics, 1 (1), 107-164.

[19] Karatzas, K., \& Moussiopoulos, N. (2000). Development and use of integrated air quality management tools in urban areas With the aid of 
International Journal of Engineering Research and Technology. ISSN 0974-3154 Vol.13, No.3 (2020), pp. 490-499

(C) International Research Publication House. https://dx.doi.org/10.37624/IJERT/13.3.2020.490-499

environmental telematics. Environmental Monitoring and Assessment, 65 (1-2), 451-458.

[20] Fernández, LC, Alvarez, F., Gonzalez-barcala, FJ, Antonio, J., \& Portal, R. (2013). Indoor Air Contaminants and Their Impact on Respiratory Pathologiesฐ. Bronconeumología files, 49 (1), 2227.https://doi.org/10.1016/j.arbr.2012.11.004.

[21] Mart, DX, Andrea, P., \& Hern, C. (2015). Microbiological contamination of the air inside and sick building syndrome Microbiological Air pollution indoor and the sick building syndrome, 37-50.

[22] Hwang, SH, \& Park, WM (2019). Indoor air quality assessment With respect to airborne culturable bacteria, volatile organic compounds Total, formaldehyde, PM10, CO2, NO2, O3 and in underground subway stations and parking lots. Air Quality, Atmosphere and Health, (2).

[23] Rafael, S., Vincent, B., Rodrigues, V., Miranda, AI, Borrego, C., \& Lopes, M. (2018). Impacts of green infrastructures on aerodynamic fl ow and air quality in Porto 's urban area. Atmospheric Environment, 190 (July), 317-330. 